\title{
CIUDADANÍA LABORAL: CRÍTICA Y DEFENSA DE UN CONCEPTO JURÍDICO-POLÍTICO*
}

\author{
FERNANDO MUÑOZ LEÓN**
}

RESUMEN: Nuestra jurisprudencia laboral, tanto en sede administrativa como judicial, acostumbra invocar la noción de 'ciudadanía laboral' para proteger diversos 'derechos fundamentales' de los trabajadores, particularmente su privacidad y su honra. Esta práctica discursiva resignifica el concepto de ciudadanía, el cual normalmente remite a la inclusión igualitaria de todos los integrantes de una comunidad en la toma de decisiones relevantes para esta. Esta resignificación del concepto de ciudadanía parece no solo teóricamente innecesaria $-y$, en consecuencia, injustificada a la luz del principio metodológico de parsimonía- sino también programáticamente inconveniente. Convencer a los trabajadores de que su ciudadanía laboral está protegida cuando se les protegen intereses individuales obscurece la meta histórica -política y jurídica- de emancipar a la clase trabajadora. Tal emancipación solo se alcanzará una vez que la relación contractual entre trabajadores y empleadores haya salido del plano de la subordinación y dependencia para entrar en el de la inclusión igualitaria; esto es, en el de la ciudadanía.

PALABRAS CLAVE: Dominación y ciudadanía - emancipación de los trabajadores - teoría crítica del derecho

\section{LABOR CITIZENSHIP: CRITICISM AND DEFENSE OF A JURIDICO-POLITICAL CONCEPT}

ABSTRACT: Our labor case law, in both its administrative and judicial versions, invokes the notion of 'labor citizenship' to protect various 'fundamental rights' of workers, particularly their privacy and their honor. This discursive practice resignifies the concept of citizenship, which normally denotes the egalitarian inclusion of all the members of a community in the adoption of decisions that are consequential for the

Fecha de recepción: 16 de enero de 2013.

Fecha de aceptación: 26 de septiembre de 2013.

** Doctor en Derecho, Universidad de Yale. Profesor Auxiliar, Facultad de Ciencias Jurídicas y Sociales, Universidad Austral de Chile. Correo electrónico: fernando.munoz@uach.cl 
community at stake. This resignification of the concept of citizenship seems not only unnecessary -and, thus, unjustified in light of the methodological principle of parsimony- but also programmatically inconvenient. To convince workers that their labor citizenship is protected when their individual interests are protected obscures the historical -political and juridical-goal of emancipating the working class. This emancipation will only be achieved once the contractual relation between workers and employers has left the realm of subordination and dependence to enter that of egalitarian inclusion; that is to say, that of citizenship.

KEY WORDS: Domination and citizenship - workers emancipation critical legal theory

\section{I) INTRODUCCIÓN: LA CRATOLOGÍA DE LOS CONCEPTOS JURÍDICOS}

Es habitual que en el discurso jurídico, tal como en toda otra área del conocimiento estructurada en torno a conceptos, cada cierto tiempo aparezcan nociones, ideas o vocablos que logren ganar el favor de los hablantes. Esto ocurre con particular éxito cuando los nuevos conceptos parecen reflejar el espíritu de los tiempos; cuando parecen expresar nuevas realidades para las que el léxico tradicional no estaba construido.

El problema es que, en ocasiones, dichos nuevos conceptos pueden crear en nosotros la ilusión de que nuevas realidades han efectivamente surgido, en circunstancias de que no estamos sino frente a vino viejo en odres nuevos. En tales casos los conceptos fracasan en su labor de describir fenómenos, descripción que en el caso del derecho cumple la importantísima función de "distinguir los intereses protegidos por el derecho de

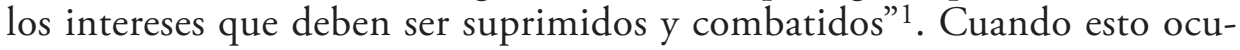
rre, los conceptos mistifican en lugar de clarificar; crean una percepción singularmente distorsionada de la realidad, una falsa conciencia. Ideología, en la definición más clásica $-y$, hay que reconocerlo, epistemológicamente más conservadora- de la palabra ${ }^{2}$.

El gran problema, por supuesto, no es la verdad o falsedad de nuestra representación de la realidad sino el impacto de dicha representación

Luhmann, Niklas (1992). "Operational closure and structural coupling: the differentiation of the legal system”. Cardozo Law Review, Vol. 13, pp. 1419-1441, p. 1430.

"A grandes rasgos, un linaje central, desde Hegel y Marx a Georg Lukács y algunos pensadores marxistas posteriores, ha estado concentrado en las ideas de verdadera y falsa cognición, con la ideología como ilusión, distorsión y mistificación; mientras que una tradición de pensamiento alternativa ha sido más sociológica que epistemológica, preocupada más con la función de las ideas dentro de la vida social que con su realidad o irrealidad". Eagleton, Terry (1991) Ideology: an introduction. London: Verso, 242 pp., p. 3. 


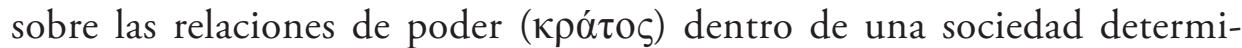
nada $^{3}$. ¿Favorecerá ella la isocracia, es decir la igualación en las relaciones de poder? ¿O redundará en el ensanchamiento anisocrático de las diferencias de poder? Por ello es significativo seguir empleando lo ideológico como una categoría de la teoría social; o, más bien, volver a emplearla. Pero tal retorno a lo ideológico, se entiende, no debe apuntar al sentido exclusivamente epistémico del término, sino que a su sentido cratológico; esto es, debe apuntar al impacto de nuestros conceptos en las estructuras de poder socialmente existentes. $Y$, en ese sentido, el estudio de la ciencia jurídica -entendida como el sistema de conceptos jurídicos empleados por los sujetos de derecho para describir la realidad social- constituye una área del análisis social donde el estudio de lo ideológico -entendido como el estudio de las consecuencias cráticas de nuestras formas de representacióncobra particular relevancia ${ }^{4}$.

Una forma en la cual el derecho en las sociedades occidentales ha jugado un rol ideológico ha sido creando estructuras jurídicas que, detrás de su pretendida imparcialidad a la identidad social de los sujetos de derecho, esconden estructuras de privilegio y desventaja. Así ocurre con "la majestuosa equidad de las leyes que prohíben, tanto al rico como al pobre, acostarse bajo los puentes, mendigar en las calles y robar pan" 5 . Otra estrategia ideológica, y que es la que me interesa aquí, es la de introducir conceptos que nos hacen pensar que las cosas están mejor de lo que están:

3 Así, por ejemplo, Flyvbjerg realiza un llamado a incluir las discusiones sobre el poder, sobre "quién gana y quién pierde; mediante qué mecanismos de poder" en el contexto de una ciencia social fronética, es decir orientada al conocimiento práctico sujeto a valores (fronesis) y, como tal, distinguida nítidamente de la episteme y de la tecné. FlYvbJerg, Bent (2001) Making Social Science Matter: Why Social Inquiry Fails and How it Can Succeed Again. Cambridge: Cambridge University Press, 216 pp., p. 60. Como el autor observa, dichas preguntas sobre el poder "son formuladas con la conciencia de que no existe un 'nosotros' unificado en relación al cual las preguntas puedan recibir una respuesta definitiva. El investigador fronético no percibe ningún punto neutral, ninguna 'mirada desde ningún lugar', para su trabajo”. Flyvbjerg (2001) 60-61.

4 Como observa Collins, escribiendo sobre la crítica marxista del derecho occidental, "los marxistas enfatizan la importancia de la ideología dominante en demarcar las fronteras de la acción política aceptable. La clase dominante usa su posición para diseminar a lo largo de la sociedad su propia visión del mundo y sus valores. Si es exitosa en la propagación de la ideología dominante, entonces el sentido común de todos sobre lo bueno y lo malo, lo racional y lo irracional, e incluso en materia de juicios estéticos, estarán formadas por la asimilación de ideas proporcionadas por agentes de la clase dominante... El sistema jurídico juega un rol vital aquí. En particular, el entramado jurídico de reglas y doctrinas provee una interpretación y evaluación comprehensivas de las relaciones y eventos sociales que está a tono con los temas principales de la ideología dominante. Ya que el sistema jurídico es encontrado frecuentemente en la vida cotidiana, su sistemática articulación y diseminación de una ideología dominante se encuentra entre los principales mecanismos para el establecimiento de la hegemonía ideológica”. Collins, Hugh (1984) Marxism and Law. Oxford: Oxford University Press, 159 pp., p. 50.

$5 \quad$ France, Anatole (1921) The red lily. London: John Lane, 325 pp., p. 95. 
que las fuentes sociales de la desventaja se encuentran jurídicamente identificadas y combatidas, y los desaventajados, protegidos por el derecho ${ }^{6}$.

De alguna forma, toda proclamación formal de derechos desprovista de un efectivo acceso a los bienes que son objeto de dichos derechos no es más que eso. Por supuesto, los catálogos de derechos -tanto las diez primeras enmiendas a la Constitución de Estados Unidos como nuestro propio artículo 19 de la Constitución- pueden argüir en su favor que, como mínimo, le entregan a los desaventajados términos y nociones con los cuales articular sus reclamos contra el sistema. Libertad, igualdad, debido proceso, educación, trabajo, integridad física y psíquica serían, si bien no efectivas protecciones constitucionales, a lo menos marcadores retóricos que permitirían explicitar qué es lo que está mal con el privilegio de los privilegiados alcanzado a costa de la desventaja de los desaventajados.

Ahora bien, más preocupante todavía es el efecto ideológico -mistificador- de los conceptos empleados en aquellas áreas del derecho que se vinculan directamente con la protección de los desaventajados y que, al menos en teoría, deberían estar encargadas de hacer realidad las promesas constitucionales formuladas a estos. Allí, un riesgo particularmente significativo es que los conceptos terminen confundiendo a los desaventajados, haciéndoles creer que gozan de ciertas titularidades jurídicas - de ciertos derechos- cuando ello en realidad no es así; pasándoles 'gato por liebre', según la expresión popular. Este riesgo puede presentarse cuando términos con un significado teórico preciso son empleados impropiamente, particularmente cuando ello ocurre sin que existan motivos evidentes o razonablemente colegibles para tal resignificación. Tal resignificación mistificadora cumple su máximo papel ideológico cuando distorsiona el significado de términos fundamentales; de términos que constituyen premisas para vastas áreas del derecho y que inciden sustancialmente en la configuración jurídica de las relaciones sociales de poder ${ }^{7}$. En tales casos, la confusión conceptual se transforma en una mistificación anisocrática.

6 Así, opina Novoa, la consideración de las "aspiraciones, intereses y reacciones subjetivas que suscitan en los seres humanos el sistema de organización social establecido o sus cambios posibles" y su vinculación con las diversas formaciones discursivas o “ideologías", en el segundo sentido identificado por Eagleton, "serán de utilidad para desnudar formas contingentes de teorización jurídica y poner al descubierto que ellas no representan, como se ha pretendido, la única y genuina forma de expresión de la justicia y el orden, sino que son instrumentaciones jurídicas reaccionarias, elaboradas por los sustentadores de un régimen capitalista establecido para beneficio de un reducido sector social". NovoA, Eduardo (1983) Derecho, politica y democracia: un punto de vista de izquierda. Bogotá: Editorial Temis, 229 pp., p. 13-14.

7 En efecto, "una estructura discursiva no es meramente una entidad 'cognitiva' o 'contemplativa'; es una práctica articulatoria que constituye y organiza las relaciones sociales”. LACLAU, Ernesto y Mouffe, Chantal (2001) Hegemony and Socialist Strategy. London: Verso, 240 pp., p. 96. 
Esto ocurre hoy en nuestro país en cuanto a la noción de 'ciudadanía laboral', que "ha tenido particular éxito" 8 como rótulo para la protección de variados intereses individuales de los trabajadores, particularmente en materia de protección a la privacidad y la honra ${ }^{9}$. Desde una perspectiva teórica, tal resignificación es innecesaria, toda vez que ya existe un concepto para referirse a la protección de los intereses en cuestión: el concepto de 'derechos fundamentales' ${ }^{10}$. Esto hace que la práctica discursiva en estudio sea una multiplicación más allá de lo necesario de las entidades: una infracción al principio metodológico de la parsimonia ${ }^{11}$. Lo que es más preocupante aún, desde una perspectiva política, es que la utilización que de este concepto hacen la jurisprudencia y la doctrina iuslaborales transforma la promesa de una inclusión igualitaria en la toma de decisiones, que caracteriza filosófica e históricamente al concepto de ciudadanía ${ }^{12}$, en Ugarte, José Luis (2007) El nuevo derecho del trabajo. Santiago: LexisNexis, 262 pp., p. 115.

9 La expansión de la noción de 'ciudadanía' hacia el lugar de trabajo puede ocurrir de otras formas; formas superficiales, por ejemplo, que hagan referencia a características adjetivas de la ciudadanía. Así, en la literatura del management y de la psicología aplicada a este campo ha surgido un concepto que, debido a su cercanía con la noción de ciudadanía laboral, vale la pena mencionar al menos: el concepto de 'ciudadanía en el lugar de trabajo (workplace citizenship), también denominado como 'ciudadanía organizacional' (organizational citizenship). Los autores que trabajan en esta línea toman del concepto de ciudadanía propio de la historiografía republicana la idea de que el ciudadano se siente afectiva y normativamente vinculado hacia la nación de la cual es parte, vínculo que se traduce en el cultivo de diversas 'virtudes cívicas'; es decir, de comportamientos altruistas y desinteresados que benefician a la comunidad toda sin necesariamente involucrar recompensas para los individuos. Así definida, la ciudadanía en el lugar de trabajo sería aquel "[c]omportamiento individual que es discrecional, no directa o explícitamente reconocido por el sistema formal de recompensas, y que en conjunto promueve el eficiente y efectivo funcionamiento de la organización". Podsakoff, Philip, MacKenzie, Scott y Organ, Dennis (2006) Organizational Citizenship Behavior: Its Nature, Antecedents, and Consequences. Thousand Oaks: Sage, 360 pp., p. 3. Como ejemplos se cita el "tolerar imposiciones temporales sin quejarse" o "formular a personas ajenas a la unidad de trabajo comentarios oportunos y constructivos sobre esta o sobre su personal directivo". Bateman, Thomas y Organ, Dennis (1983). "Job Satisfaction and the Good Soldier: The Relationship between Affect and Employee 'Citizenship". The Academy of Management Journal, Vol. 26, pp. 587-595, p. 588. Como se ve, esta línea de análisis centra su preocupación en la utilidad, beneficio o interés de la unidad productiva, y con ello, de manera mediata, en el interés de aquellos quienes se benefician de la productividad de la unidad productiva; es decir, en sociedades capitalistas, en los dueños del capital.

10 En una inconsistencia que pondría aún más nervioso todavía al proverbial Occam, este concepto también es empleado por la jurisprudencia que aquí será discutida.

11 Para un examen desde la perspectiva de las ciencias sociales del principio de parsimonia, a menudo asociado a la figura del franciscano Guillermo de Occam, véase GerRing, John (2001) Social Science Methodology: A Criterial Framework. Cambridge: Cambridge University Press, 324 pp., y SARTORI, Giovanni (2011) Logica, metodo e linguaggio nelle scienze sociali. Bologna: Società Editrice Il Mulino, 288 pp., p. 129.

12 "En contextos filosóficos, 'ciudadanía' se refiere a un ideal normativo substantivo sobre la membresía y la participación en una comunidad política. Ser ciudadano, en este sentido, es ser reconocido como un miembro pleno e igual de la sociedad, con el derecho a participar en el proceso político. Como tal, es un ideal característicamente democrático... Este vínculo 
un tímido velo que recubre la intimidad del trabajador individual. Ello oscurece -mistifica- el hecho de que las relaciones sociales jurídicamente permitidas $-y$, por lo tanto, protegidas- por nuestro derecho del trabajo permanecen situadas en un contexto de subordinación y dependencia; es decir, de dominación, y en consecuencia, de negación de la inclusión igualitaria o ciudadanía.

¿Cuánto han cambiado las cosas desde que Marx clamara que, ante el evento de una revolución, las clases trabajadoras solo tenían sus cadenas por perder? La desoladora respuesta es que, si bien en algún momento bastante había cambiado en nuestro país ${ }^{13}$, hoy existen menos motivos para el optimismo. Y aunque las acciones llevadas a cabo por nuestros tribunales en nombre de la ciudadanía laboral efectivamente representen una mejoría respecto del trato recibido por los trabajadores a mediados del siglo XIX, la resignificación que del concepto de ciudadanía hace el discurso jurídico que acompaña a tales acciones contribuye a diluir el proyecto histórico de la emancipación del trabajador; de su adquisición de ciudadanía, de ilustración y de mayoría de edad ${ }^{14}$.

A continuación examinaré los orígenes en la teoría social de posguerra de la vinculación entre ciudadanía y clase social y las transformaciones de dicho concepto, para posteriormente revisar la recepción de esta construcción en el discurso jurídico nacional. Contra la modalidad nacional de este concepto erigiré una teoría positiva de la ciudadanía laboral, con la que intentaré delinear qué implicancias tendría el importar al ámbito laboral una noción normativamente substantiva de ciudadanía.

entre ciudadanía y democracia es evidente en la historia del pensamiento occidental... De hecho, a veces es difícil distinguir entre ciudadanía, como un tópico filosófico, de democracia”. Craig, Edward (1998) Routledge Encyclopedia of Philosophy, Vol. 7. London: Routledge, 868 pp., p. 362.

13 "En la República de Chile, la legislación social, comprendiéndose en ella, tanto la del trabajo, como la de la previsión social, ha alcanzado en los últimos 25 años un notable progreso, que la coloca en un lugar preponderante dentro del continente americano. En ciertas materias, como la protección de los empleados particulares, las leyes chilenas son tal vez las más completas en Latino América". WAlker, Francisco (1948). "Legislación Social de Chile". Anales de la Facultad de Ciencias Jurídicas y Sociales, Vol. 13, No 52-59, p. 33-41, p. 33. Hoy la realidad es totalmente la opuesta; parafraseando a Walker, podríamos decir que la legislación social, tanto la del trabajo como la de la previsión social, ha experimentado en los últimos 33 ańos un abismante retroceso, que la coloca en una posición menoscabada dentro del continente americano, y no sería aventurado sostener que en ciertas materias, como la protección y promoción de la sindicalización, las leyes chilenas son tal vez las más insatisfactorias de Latinoamérica.

14 "Ilustración es la salida del ser humano de su minoría de edad, de la cual él mismo es culpable. Minoría de edad es la incapacidad de servirse del propio entendimiento sin dirección de otro. Él mismo es culpable de esta minoría porque la causa de la misma radica no en un defecto del entendimiento sino en la falta de decisión y del coraje de servirse del propio sin la dirección de otro. ¡Sapere aude! ¡Ten el coraje de servirte de tu propio entendimiento! es, en consecuencia, la divisa de la Ilustración”. Kant, Immanuel (2000) Crítica de la Razón Pura. ¿Qué es Ilustración?. Zaragoza: Publicacions de la Universitat de València, 92 pp., p. 63. 


\section{1) GENEALOGÍA Y TRANSFORMACIONES DE LA CIUDADANÍA LABORAL}

¿Cómo surge el concepto de ciudadanía laboral? ¿Qué procesos históricos dan cuenta de su formulación? Los primeros pasos hacia la formulación de este concepto fueron dados en Europa. Hay que distinguir al respecto dos etapas. La primera de ellas corresponde a la época de posguerra, fase en la cual la vinculación entre ciudadanía e identidad de clase emerge como correlato subjetivo del Estado de Bienestar. La segunda corresponde a la era finisecular, cuando la crisis del Estado de Bienestar y el reemplazo de la clase trabajadora por el trabajador individual como espacio privilegiado para la articulación de discursos reivindicatorios genera significativas transformaciones en la agenda iuslaboral y en sus énfasis temáticos.

El paradigma conceptual que prevalece en la primera etapa, la de auge del Estado de Bienestar, está formulado por el sociólogo Thomas Humphrey Marshall en su famoso ensayo Ciudadanía y Clase Social, de 1949. La relevancia del planteamiento de Marshall es que proporciona un patrón argumentativo cuyos ecos se sienten hasta el día de hoy; incluso, se podría sostener, en la práctica jurisprudencial discutida en este trabajo. Dicho modelo consiste en expandir el ámbito de la ciudadanía, haciéndola rebasar las fronteras que el imaginario liberal le imprime -esto es, el dominio público de lo político-electoral- para incorporar en ella derechos y garantías de carácter más 'social'.

En reemplazo de la teorización liberal, Marshall formula un concepto de ciudadanía integrado por tres elementos o componentes de esta que se van incorporando de manera paulatina a lo largo de la historia: el elemento civil, "compuesto de los derechos necesarios para la libertad individual", tales como la libertad de expresión o el derecho de propiedad; el elemento político, consistente en "el derecho a participar en el ejercicio del poder político, como integrante de un cuerpo revestido de autoridad política o como elector de los integrantes de dicho cuerpo"; y el elemento social, expresado en un conjunto de titularidades que van "del derecho a un mínimo de bienestar y seguridad económica al derecho a participar en plenitud de la herencia social y a vivir la vida de un ser civilizado de acuerdo a los estándares prevalecientes en la sociedad"15. En el análisis de Marshall, cabe observar, cada uno de estos elementos -esto es, lo civil, lo político, lo social- se va incorporando sucesivamente al concepto de ciudadanía en distintas etapas de la historia político-constitucional de Inglaterra, correspondientes respectivamente a los siglos XVIII, XIX, y XX ${ }^{16}$.

15 Marshall, Thomas (2006). "Citizenship and Social Class". En Pierson, Christopher y Castles, Francis (editores). The Welfare State Reader. Cambridge: Polity Press, pp. 30-39, p. 30.

16 El análisis de Marshall es complementado por Albert Hirschmann, quien estudia las estrategias retóricas empleadas históricamente por los opositores a cada uno de los actos mediante los cuales se incluyeron nuevos derechos dentro del concepto marshalliano de ciudadanía. 
La premisa que subyace a esta categorización histórica de las transformaciones de la ciudadanía consiste en afirmar, en palabras de Marshall, que ella es "un estatus conferido a aquellos quienes son miembros plenos de una comunidad", en cuya virtud "todos quienes poseen el estatus son iguales respecto de los derechos y deberes de los cuales el estatus está compuesto" 17 . La ciudadanía sería, en ese sentido, una categoría formal cuyo contenido varía de acuerdo a las mutaciones de la realidad categorizada: como lo pone Marshall, "no existe un principio universal que determine cuáles serán dichos derechos y deberes, sino que las sociedades donde la ciudadanía es una institución en desarrollo crean una imagen de lo que sería la ciudadanía ideal con la cual pueden medir sus logros y hacia la cual pueden ser dirigidas las aspiraciones" 18 .

Ahora bien, Marshall observa que la ciudadanía así definida se contrapone con la clase social, que es "un sistema de desigualdad"19. Esta contraposición no puede conducir a priori al triunfo de la ciudadanía por sobre la estructura de clase ya que, en la sociedad contemporánea, la estructura de clase "es considerada como necesaria y funcional" puesto que "provee incentivos para el esfuerzo y diseña la distribución del poder" dentro de la sociedad ${ }^{20}$. Aun así, señala Marshall, los dramas asociados a la pobreza han despertado niveles de conciencia social que han llevado a transformar a la reducción de las desigualdades de clase (class-abatement) en "un objetivo deseable a ser buscado tanto como sea compatible con la eficiencia continua de la maquinaria social" ${ }^{21}$. Por ello, según nuestro autor, a principios del siglo XX el objetivo de la reducción de las desigualdades de clase "se orientó, a menudo de manera bastante deliberada, a hacer al sistema de clase menos vulnerable a los ataques al aliviar sus consecuencias menos deseables" 22 . Posteriormente, a medida que diversas fuerzas económicas y políticas fueron desplegando su acción sobre la estructura inglesa de clases ya hacia mediados del siglo XX, la reducción de las desigualdades de clases pasó de ser "un intento por disminuir los evidentes

Véase Hirschman, Albert (1991) The Rhetoric of Reaction: Perversity, Futility, Jeopardy. Cambridge: Harvard University Press, 197 pp.

17 Marshall (2006) 34.

18 Marshall (2006) 34. Me parece que Marshall extrae conclusiones conceptualmente problemáticas del hecho evidente de que la ciudadanía no significa lo mismo en todo lugar y época. El problema es que para designar al fenómeno del que Marshall habla existe otra expresión: la igualdad de derechos. Si empleamos dicha expresión para denominar al fenómeno que aborda Marshall, esto es el hecho de que los "miembros plenos de una comunidad" sean "iguales respecto de los derechos y deberes" reconocidos en el sistema en cuestión, entonces podemos reservar la ciudadanía para denominar a un tipo específico de derecho consistente en el derecho a participar de las decisiones que afectan a dicha comunidad.

Marshall (2006) 34.

Marshall (2006) 34.

Marshall (2006) 34.

Marshall (2006) 34. 
males de la pobreza en los segmentos más bajos de la sociedad" a transformarse en "acción orientada a modificar todo el patrón de la desigualdad social", aspiraciones "logradas en parte incorporando derechos sociales en el estatus de la ciudadanía y así creando un derecho universal a ingreso real no vinculado al valor de mercado del demandante" 23 .

De esta manera, en algún momento el proyecto de la ciudadanía social pudo ser presentado en algún sentido como un intento por abolir, si es que no la estructura de clases en sí misma, a lo menos su impacto en la distribución social de recursos, mediante el establecimiento de garantías universales en el acceso a diversos bienes (salud, educación) y mediante subsidios focalizados al acceso a otros bienes (ingresos, vivienda); es decir, mediante el establecimiento de derechos sociales. En este contexto, el gran aporte de la matriz conceptual de Marshall consiste en evidenciar que cada uno de estos elementos -el civil, el político y el social- es necesario para poder sostener que se es miembro en plenitud de una comunidad política; que esta condición solo la alcanzan quienes acceden de manera efectiva a todos los beneficios producidos por el intercambio social. Solo un sujeto libre de las preocupaciones ocasionadas por "la recurrente necesidad a la cual toda la vida humana está sujeta" 24 , emancipado de la cuestión social y de la "existencia de la pobreza" 25 , puede desplegar el tipo de vita activa que para Arendt caracteriza al dominio de lo político y de la libertad y que es propio del ideal republicano de ciudadanía ${ }^{26}$. Así interpretado, el planteamiento marshalliano tiene su conclusión natural, en efecto, en una teoría republicana de la libertad como ausencia de dominación, la cual requiere que "nadie pueda interferir de manera arbitraria, discrecionalmente, en las elecciones de personas libres" 27 , un propósito que es alcanzado cuando "las personas llegan a tener iguales poderes" o existe "un régimen legal que impide a la gente dominar a otros sin que aquel domine a nadie a su vez" 28 .

En materia específicamente laboralista, el concepto de ciudadanía llega a esta disciplina por primera vez de la mano del Rapport Auroux, informe elaborado por el Ministerio del Trabajo francés en 1981. La llegada del socialista François Mitterrand a la Presidencia ese año es presentada en dicho informe como expresión de la voluntad del pueblo francés de

\footnotetext{
23 MARShall (2006) 37.

24 Arendt, Hannah (1965) On Revolution. New York: Penguin Books, 368 pp., p. 59.

25 ARENDT (1965) 60.

26 El liberalismo, por su parte, no enfatiza el aspecto 'virtuoso' de la ciudadanía, sino más bien la posibilidad conceptual que ella ofrece de atribuir, hipotética o empíricamente, la autoría de la ley a cada ciudadano, permitiendo que el orden político y legal se sustente en última instancia en la voluntad de los gobernados.

27 Petтit, Philip (1997) Republicanism: A Theory of Freedom and Government. Oxford: Oxford University Press, 388 pp., p. 271.

Pettit (1999) 273.
} 
cambio y de una "nueva ciudadanía”. Es allí donde, guiado por la afirmación de que "los trabajadores deben ser ciudadanos a tiempo completo" 29 , el Rapport defiende el respeto de diversos intereses de índole laboral al interior de la empresa, inaugurando la retórica que caracterizará a las posteriores transformaciones de dicho concepto.

Ahora bien, las crisis experimentadas por el propio Estado de Bienestar a partir de mediados de los 70 se tradujeron en diversas crisis del concepto 'social' de ciudadanía, y a consecuencia de ello en ciertas mutaciones del mismo. A partir de la crisis del petróleo, hito coincidente con el golpe de Estado en Chile, diversas fuerzas políticas en todo Occidente comenzaron una embestida contra el heterogéneo entramado de instituciones, políticas, programas y regulaciones orientadas a generar mayores niveles de equidad mediante la intervención estatal en la economía capitalista. Las estrategias son distintas, así como su impacto; no es lo mismo acometer estas transformaciones en el Chile de Pinochet, donde la receta puede ser aplicada sin restricciones o condicionamientos provenientes de la política ${ }^{30}$, que en Estados Unidos, donde Reagan tiene que hacer frente a un Congreso primordialmente opositor a lo largo de todo su período, así como a un conjunto de agencias regulatorias altamente institucionalizadas y de funciones bien especificadas ${ }^{31}$. La filosofía inspiradora y los objetivos perseguidos, sin embargo, son los mismos: el Estado no es la solución a los problemas sino que es parte del problema, y como tal debe ser reducido. Por supuesto, la ciudadanía social marshalliana y la propia protección jurisdiccional y administrativa de los trabajadores, ambas altamente dependientes de la intervención estatal en la sociedad y la economía, se resquebrajan fácilmente bajo el fuego de los cuestionamientos así impulsados.

29 Auroux, Jean (1981) Les Droits Des Travailleurs: Rapport au Président de la République et au Premier ministre. Paris: Collection des rapports officiels La Documentation Francaise, 82 pp., p. 6.

30 En este caso, la receta se encuentra en el así llamado 'Ladrillo', programa elaborado por un grupo de economistas conocidos popularmente como 'Chicago Boys' para la candidatura presidencial de Jorge Alessandri de 1970 y que finalmente fue impuesto desde importantes puestos ministeriales con el respaldo militar a partir de 1973. Véase VALDÉs, Juan Gabriel (1995) Pinochet's Economists: The Chicago School in Chile. Cambridge: Cambridge University Press, 334 pp.

31 Para un análisis de los fracasos en la revolución reaganiana, véase ACKERMAN, Bruce (1991) We the People: Foundations. Cambridge: Harvard University Press, 369 pp., у Sкоwronek, Stephen (1997), The Politics Presidents Make: Leadership from John Adams to Bill Clinton. Cambridge: Harvard University Press, 546 pp., p. 409 y ss. Vistos a la luz de los sucesos posteriores, habría que concluir que diversos aspectos de la revolución reaganiana fueron llevados adelante por Clinton, quien le puso un 'fin al bienestarismo tal como lo conocemos' (an end to welfare as we know it), y por Bush II, que llevó a nuevos extremos la desregulación y el sofocamiento de programas estatales mediante la reducción impositiva y el aumento, paralelamente, del gasto en defensa en niveles siderales. 
Eso no es todo, por cierto. Si la ciudadanía social y el derecho del trabajo son la expresión jurídico-institucional de la identidad de la clase trabajadora, su expresión política es el socialismo, lato sensu; es decir, aquella variedad de movimientos partidarios que reclaman para sí, con diversos grados de éxito, la representación de los trabajadores mediante la capacidad de traducir sus intereses y necesidades en programas de acción política y de reforma legal. Definido así, en términos lo más comprehensivos posibles, el socialismo en Occidente incluía a variados actores ubicados desde el centro a la izquierda del espectro político; social cristianos, laboristas, socialdemócratas, socialistas, comunistas. Inevitablemente, entonces, el discurso sobre la relación entre ciudadanía y clase social, y el derecho del trabajo mismo, reflejaron las transformaciones que estos proyectos políticos experimentaron durante el último cuarto del siglo $\mathrm{XX}$, a menudo bajo el rótulo de su 'renovación'.

Ahora bien, es importante reseñar que dicha renovación apuntó en más de una dirección. Por un lado, para algunos la crisis de "toda una concepción del socialismo fundada en la centralidad ontológica de la clase trabajadora" 32 resultó en el desplazamiento de dicha lucha del lugar protagónico que había tenido y su remplazo por una serie de batallas más locales: algunas de ellas, a la diferencia y reconocimiento de colectivos subalternos distintos de la clase trabajadora; otras, a la reivindicación de temáticas aún más alejadas de la matriz histórica del socialismo, tales como el ambientalismo o el animalismo. Por el otro, para otros la crisis se tradujo en el "frío" y la "vergüenza" de la "desnudez", en la pérdida del "cuerpo teórico" y de las "convicciones inconmovibles, protectoras, fundantes" que alguna vez fundaran la acción política socialista ${ }^{33}$, vacío rellenado mediante la adopción de una fe sicambra en el mercado ${ }^{34}$. Ambas transformaciones del proyecto político socialista tiene un impacto en el proyecto jurídico laboralista, pues colaboran en la sustitución de la

32 Laclau y Mouffe (2001) 2.

33 Tironi, Eugenio (1984) La Torre de Babel. Ensayos de critica y renovación política. Santiago: Ediciones Sur, 157 pp., p. 26. Como escribiría Giddens en defensa de un proyecto político surgido de crisis similares a esta, "el socialismo y el comunismo han muerto, y sin embargo [sus fantasmas] todavía nos rondan. No podemos dejar de lado los valores e ideales que los inspiraron, pues algunos siguen siendo intrínsecos a la buena vida cuya creación es el punto del desarrollo social y económico. El desafío es hacer que estos valores cuenten allí donde el programa económico del socialismo ha sido desacreditado”. Giddens, Anthony (1998) The Third Way: The renewal of social democracy. Cambridge: Polity Press, 166 pp., p. 1.

34 "El rey Clodoveo pidió ser bautizado en primer lugar por el Obispo. Como un nuevo Constantino se encaminó hacia la fuente bautismal, listo para lavar las llagas de su antigua lepra y para ser purificado en el agua de las lóbregas manchas que había portado por tanto tiempo. Al paso que caminaba hacia su bautismo, el santo hombre de Dios se dirigió a él con estas señeras palabras: 'Inclina humildemente tu cabeza, Sicambro. Adora lo que has quemado, quema lo que has adorado". Gregory of Tours (1991) The History of the Franks. New York: Penguin, 720 pp., p. 144. 
antes monolítica clase trabajadora; ya sea por multitudes de colectivos o bien por una muchedumbre de individuos. En este nuevo contexto, las preguntas sobre los velos y protecciones que custodian la identidad y las sensibilidades de la mujer o de diversas minorías, así como la privacidad e intimidad de los individuos genéricamente hablando, pasan a ocupar un lugar central en la discusión laboralista ${ }^{35}$.

Así es como llegamos al presente. El impacto que las tendencias y transformaciones indicadas anteriormente han tenido sobre el concepto de ciudadanía se evidencia en el tratamiento que da al asunto Hugh Collins; autor que, de escribir a mediados de los 80 un trabajo sobre marxismo y derecho ${ }^{36}$, ha pasado a titular su trabajo sobre la materia como Derecho del Empleo. Este dato es relevante debido a la observación del propio autor respecto a que esta temática ha sido "investigada bajo diversas otras etiquetas: derecho laboral, derecho industrial, derecho social", y que "diversos nombres para el tema revelan contrastes en énfasis y alcance" 37. Habría que suponer, en consecuencia, que su énfasis no está en la clase trabajadora como sujeto colectivo sino que en el empleo; concepto fetiche del imaginario contemporáneo cuyo estatus rivaliza solo con el del emprendimiento.

En cuanto al tema aquí en discusión, Collins sostiene que el término ciudadanía sigue siendo empleado en la discusión europea sobre el mercado del trabajo de una manera que excede "la tradicional versión liberal de titularidades del ciudadano a participar en un sistema democrático de gobierno y a gozar de protección en sus libertades civiles contra el abuso del poder estatal"38. Ahora bien, según Collins, aun cuando este concepto hoy "incluye un rango más amplio de asuntos sociales, tales como educación, cultura y empleo" y en virtud de ello "los ciudadanos tienen derechos sociales fundamentales también; a tener acceso a la educación, al cuidado de su salud, a actividades culturales, y a trabajos", la concepción contemporánea del mismo también incorpora al discurso la precisión de que esos derechos no son concebidos como "titularidades bienestaristas"

Resumiendo varias de las dinámicas anotadas, Alonso observa que "paralelamente a la pérdida de coherencia y a la minimización del sistema de garantías de la red de derechos de bienestar -fundamentalmente de origen laboral- que se consideraban asociados inseparablemente al ciudadano contemporáneo (trabajador, masculino, maduro, etc.), se desataba una fuerte polémica, con críticas y replanteamientos en profundidad de la naturaleza distribucionista e igualitarista (abstracta) de la ciudadanía social... Se apresuraban muchos, así, a dar por superada la identidad y la identificación automática entre trabajador fordista nacional normalizado y ciudadano, buscando con ello nuevas formas de grupalidad, identidad y diferencia para fundamentar una ciudadanía de nuevo tipo". Alonso, Luis (2007) La Crisis de la Ciudadanía Laboral. Barcelona: Anthropos, 287 pp., p. 15-16.

36 Collins (1984).

37 Collins, Hugh (2010) Employment Law. Oxford: Oxford University Press, 265 pp., p. 5.

38 Collins (2010) 24. Recordemos, eso sí, que este concepto no solo tiene formulaciones liberales sino también republicanas, que difieren de la señalada por el autor. 
sino que "dependen de que el ciudadano respete sus responsabilidades también" 39 . En esta última afirmación se percibe el eco de Giddens, quien argumenta que la nueva política que viene a reemplazar al socialismo, la "tercera vía", se inspira en la idea de que "no hay derechos sin responsabilidades" ${ }^{40}$; sintonía que habría que entender como sintomática en cuanto a la distancia que a su vez Collins pareciera tomar respecto de las concepciones clásicas del laboralismo.

¿Qué especificidad tiene hoy, entonces, la noción de ciudadanía en el lugar de trabajo? Pareciera ser que, en una época en que el componente social de la ciudadanía pierde terreno, ganan protagonismo otras temáticas, más vinculadas a la esfera individual de los trabajadores que a la colectiva de clase; al elemento civil de la ciudadanía antes que al social, en la terminología de Marshall. Asuntos tales como la protección de la privacidad de las comunicaciones electrónicas y telefónicas de los trabajadores frente a su empleador, o la protección de la libertad de expresión de los trabajadores que denuncian prácticas ilegales (whistleblowers) frente al poder disciplinario de sus empleadores, llevan a Collins a afirmar que "el anterior fuerte contraste entre la esfera pública de los derechos y la esfera privada de las relaciones de mercado en la cual las libertades cívicas no tenían aplicación está siendo crecientemente cuestionada"; ya "no se acepta que el trabajador deje sus derechos ciudadanos en la puerta de su lugar de trabajo. La pregunta es, en cambio, en qué extensión deben ser protegidas las libertades cívicas contra el ejercicio de un empleador de su poder de mercado" 41 .

Collins, por cierto, parece estar consciente del desplazamiento que el concepto de ciudadanía empleado en estos casos opera respecto del laboralismo tradicional; según él mismo anota, los antiguos abogados laboralistas se caracterizaban por una desconfianza hacia "la retórica de derechos individuales" 42 , entre otras razones porque "en última instancia la fuerza de los trabajadores requiere que trabajen en conjunto, solidariamente, como una entidad colectiva" 43 . Ahora bien, en opinión de Collins, "si bien el lenguaje de los derechos puede legítimamente ser acusado de desviar la discusión jurídica hacia la dirección de las tres ' $D$ ' -'descontextualización, despolitización, y descolectivización'- estas pendientes deben ser balanceadas con el posible uso instrumental de los derechos" ${ }^{44}$; por el avance de los intereses de los trabajadores mediante el uso estratégico de ciertos reclamos jurídicos formulados incluso en los términos más in-

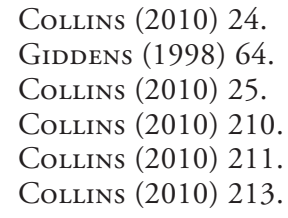


dividualistas. Así y todo, es importante que tomemos nota del reconocimiento que hace Collins a las limitaciones y consecuencias de la estrategia iusfundamental, pues ella está directamente vinculada a la crítica que es objeto de este artículo.

\section{2) LA RECEPCIÓN NACIONAL DE LA CIUDADANÍA LABORAL}

La historia de la inserción en el discurso jurídico local de la locución 'ciudadanía laboral' se inicia con la Ley No 19.759, que modificó el Código del Trabajo para incorporar a este cuerpo legal disposiciones referentes a nuevas modalidades de contratación, al derecho de sindicación, a la no discriminación arbitraria en el empleo, y a los derechos fundamentales del trabajador.

Esta inserción se inicia con los primeros actos que dieron origen a esta reforma. Así, en el Mensaje Presidencial, firmado por José Miguel Insulza en su condición de Vicepresidente de la República, leemos la rotunda afirmación del Ejecutivo según la cual "los tiempos que vivimos exigen hacernos cargo de la ciudadanía laboral que acompaña a cada persona, sea esta jefe o subordinado dentro de la empresa" ${ }^{45}$. Posteriormente, y durante la discusión del proyecto en la Comisión de Trabajo y Previsión Social del Senado, el Subsecretario del Trabajo Yerko Ljubetic observó que a nivel comparado "un conjunto de legislaciones" han intentado cautelar la "vigencia efectiva al interior de la empresa" de los "derechos fundamentales de las personas", proceso a partir del cual "se ha ido acuńando el concepto de 'ciudadanía laboral', el que se busca establecer en el proyecto, haciendo explícita la plena validez de los derechos de los trabajadores en el marco de las relaciones laborales" 46.

El término no fue mencionado nuevamente durante el resto de la tramitación de la reforma, ni tampoco fue incorporado en el texto de la misma. En lugar de ello, y en relación con la temática aquí discutida, la reforma agregó un nuevo inciso primero al artículo $5^{\circ}$ del Código del Trabajo en los siguientes términos: "El ejercicio de las facultades que la ley le reconoce al empleador, tiene como límite el respeto a las garantías constitucionales de los trabajadores, en especial cuando pudieran afectar la intimidad, la vida privada o la honra de estos" (énfasis agregado).

\footnotetext{
45 Mensaje No 136-343, Mensaje de S.E. el Presidente de la República con el que inicia un Proyecto de Ley que modifica el Código del Trabajo, 16 de noviembre de 2000, p. 4.

46 Boletín No 2.626-13, Informe de la Comisión de Trabajo y Previsión Social, recaido en el proyecto de ley, en primer trámite constitucional, que modifica el Código del Trabajo en lo relativo a las nuevas modalidades de contratación, al derecho de sindicación, a los derechos fundamentales del trabajador y a otras materias que indica, 2 de abril de 2001, p. 18.
} 
Una vez que la Ley No 19.759 entró en vigencia, la Dirección del Trabajó dio nueva proyección al concepto de ciudadanía laboral como sinónimo de la protección de intereses individuales iusfundamentales en el lugar de trabajo, incorporándolo en su jurisprudencia administrativa. El instrumento mediante el cual se llevó a cabo esta operación fue el Ordinario No 2856/162, el cual estableció una interpretación marco para el nuevo inciso ya mencionado. Este pronunciamiento menciona reiteradamente la idea de ciudadanía en su argumentación sobre el respeto a los derechos fundamentales de alcance individual en el lugar de trabajo. Por ejemplo, dicha resolución sostiene que la reforma contenida en la Ley No 19.759 materializa "el reconocimiento de la plena vigencia de los derechos fundamentales de los trabajadores en la empresa, lo que se ha denominado por la doctrina como "ciudadanía en la empresa" 47. Para el organismo administrativo, tal concepto "implica una valoración ya no simplemente del trabajo sino que de la persona que trabaja, y que a tal efecto en la Constitución está tratada no como trabajador, sino como ciudadano" ${ }^{48}$. Esta valoración se expresaría en que se hacen extensivos al espacio laboral derechos fundamentales que "sin ser netamente laborales se aplican a la relación de trabajo en cuanto son inherentes a la condición de ciudadano del trabajador" ${ }^{49}$. Entre estos derechos fundamentales "inespecíficos o de la personalidad", el citado dictamen menciona el derecho a la integridad física y psíquica, el derecho de igualdad y de no discriminación, la libertad de conciencia y de religión, el derecho al honor y a la intimidad personal, la inviolabilidad de las comunicaciones, la libertad de opinión e información, el derecho de reunión, y la libertad para el ejercicio de actividades económicas ${ }^{50}$. Así, asevera el Ordinario No $2856 / 162$, "es posible afirmar con rotundidad que, de conformidad a las normas constitucionales y en particular al inciso primero, del artículo $5^{\circ}$ del Código del Trabajo, los derechos fundamentales actúan, en nuestro

47 Ordinario No 2856/162, Departamento Jurídico, Dirección del Trabajo, Fija sentido y alcance del inciso primero, del artículo $5^{\circ}$, del Código del Trabajo, 30 de agosto de 2002, p. 1.

48 Ordinario No 2856/162, Departamento Jurídico, Dirección del Trabajo, Fija sentido y alcance del inciso primero, del artículo $5^{\circ}$, del Código del Trabajo, 30 de agosto de 2002, p. 2.

49 Ordinario No 2856/162, Departamento Jurídico, Dirección del Trabajo, Fija sentido y alcance del inciso primero, del artículo 5 ${ }^{\circ}$, del Código del Trabajo, 30 de agosto de 2002, p. 2.

50 De todos estos derechos fundamentales, el único que tiene un carácter específicamente colectivo es el derecho de reunión, mientras que varios de ellos pueden tener una significancia de carácter colectivo y, gracias a ello, político-ciudadano. El gran problema con nuestra doctrina sobre ciudadanía laboral, en definitiva, no es tanto qué derechos específicos identifica como integrantes de dicho concepto, sino qué alcance le da a dichos derechos. Hasta el momento, no ha sido capaz de escapar de las tres ' $\mathrm{D}$ ' mencionadas por Collins: descontextualización, despolitización, y descolectivización. 
sistema jurídico-laboral, como verdaderos ejes modeladores y conformadores de la idea de la 'ciudadanía en la empresa'"51.

Consecuentemente con las premisas conceptuales y los fundamentos de texto de esta apropiación de la noción de ciudadanía, la Dirección del Trabajo ha invocado la ciudadanía laboral para llevar a cabo acciones tales como establecer las condiciones en las cuales podrán ser instaladas cámaras de grabación en buses de la locomoción colectiva, situación con ocasión de la cual ha aseverado que la disposición del artículo $5^{\circ}$ ya citado "ha materializado el reconocimiento de la plena vigencia de los derechos fundamentales de los trabajadores en la empresa, lo que se ha denominado por la doctrina como "ciudadanía en la empresa" "52. Un caso más paradójico es aquel en el que la Dirección del Trabajo invalidó diversas disposiciones del reglamento interno del Supermercado Líder Arica Ltda. que restringían la libertad de expresión de los trabajadores fuera de la empresa relacionada con asuntos internos de la misma, así como la libertad de expresión de los trabajadores al interior de la empresa que versara sobre asuntos políticos ${ }^{53}$. En dicho caso, por distraerse con consideraciones genéricas sobre el concepto de ciudadanía laboral, los derechos fundamentales y el rol del principio de proporcionalidad en la limitación de estos, la Dirección del Trabajo desperdició la oportunidad de poner la primera piedra de una auténtica teoría sobre las demandas que a la relación laboral le impone la condición de los trabajadores de ciudadanos; es decir, de participantes de la formación de opinión pública y del proceso político.

La tramitación de la reforma al proceso laboral, expresada en la Ley No 20.022, sirvió para reiterar la idea según la cual la noción de 'ciudadanía laboral' habría sido importada a nuestro ordenamiento jurídico por la Ley No 19.759. Así, el Mensaje del Ejecutivo observó que la ampliación de la competencia de los juzgados laborales para conocer las causas derivadas de actos de discriminación o de actos que vulneren los derechos fundamentales de los trabajadores en el ámbito de las relaciones laborales responde "a las modificaciones ya aprobadas para el Código por la Ley No 19.759, relativas a la prohibición de discriminaciones (artículo 20) y a las normas que consagraron la idea de ciudadanía laboral en la empresa (inciso primero del artículo 5\%), en cuanto se reconoce la función limitadora de

\footnotetext{
51 Ordinario No 2856/162, Departamento Jurídico, Dirección del Trabajo, Fija sentido y alcance del inciso primero, del artículo 5o, del Código del Trabajo, 30 de agosto de 2002, p. 2.

52 Ordinario No 2328/130, Departamento Jurídico, Dirección del Trabajo, Pronunciamiento sobre la legalidad del sistema de grabación de la imagen y el sonido, a través de videocámaras instaladas en los vehículos de la locomoción colectiva urbana recaído en solicitud de Sindicato Interempresa de Trabajadores de San Bernardo Las Condes, 19 de julio de 2002, p. 2.

53 Ordinario No 3416/049, Departamento Jurídico, Dirección del Trabajo, Pronunciamiento sobre impugnación de artículos de Reglamento Interno de la empresa Hipermercado Arica Ltda. recaido en solicitud de Sindicato de Trabajadores de la empresa Supermercado Lider Arica, 28 de agosto de 2009.
} 
los derechos fundamentales respecto de los poderes empresariales en el seno de la relación de trabajo" 54 . Por su parte, el Primer Informe de la Comisión de Trabajo y Seguridad Social observó que el concepto de "derechos fundamentales de los trabajadores" está "estrechamente unido al de ciudadanía laboral, cuyo fondo doctrinario se basa en la mayor dignidad del trabajador en su empleo", en términos tales que "los derechos del trabajador emanados de su calidad de ciudadano no pueden ser rebasados por órdenes, instrucciones o reglamentos del empleador por el hecho de estar dentro de la empresa" 55 .

La propia reforma procesal laboral proveyó de un nuevo vehículo para la expansión de la práctica discursiva aquí criticada. En la actualidad, el espacio donde se invoca paradigmáticamente el concepto de ciudadanía laboral es el proceso de tutela laboral, establecido por el legislador para resolver "las cuestiones suscitadas en la relación laboral por aplicación de las normas laborales, que afecten los derechos fundamentales de los trabajadores", según reza el artículo 485 del Código del Trabajo. Así, por ejemplo, los juzgados laborales han invocado el concepto en cuestión para tutelar la intimidad y privacidad de los trabajadores durante su hora de colación ${ }^{56}$, o para cautelar la afectación a la dignidad, la integridad psíquica y la honra de trabajadores acusados infundadamente de haber cometido un robo ${ }^{57}$.

Una parte de la doctrina se ha hecho eco de esta práctica, identificando la ciudadanía en el lugar de trabajo con los así llamados derechos laborales inespecíficos, "derechos civiles y políticos que tiene el trabajador como ciudadano" 58 . Otros autores, en cambio, han expresado su escepticismo respecto a este uso del término. José Luis Ugarte, identificado equí-

54 Boletín $\mathrm{N}^{\circ}$ 3367-13, Mensaje de S.E. el Presidente de la República, con el que inicia un Proyecto de Ley que sustituye el Procedimiento Laboral contemplado en el Libro V del Código del Trabajo, p. 8. Énfasis agregado.

55 Boletín $\mathrm{N}^{\circ}$ 3367-13, Informe de la Comisión de Trabajo y Seguridad Social de la Cámara de Diputados, recaido en el Proyecto de Ley que sustituye el Procedimiento Laboral contemplado en el Libro V del Código del Trabajo, p. 62.

56 Inspección Provincial del Trabajo Nuble con Emilio Lahsen Chaer, sentencia del 26 de agosto de 2010, Juzgado de Letras del Trabajo de Chillán, RIT T-3-2010: "es posible afirmar que existe, un claro reconocimiento de la idea de 'ciudadanía en la empresa', al contemplarse en el sistema normativo constitucional no solo derechos fundamentales de corte específicamente laboral, sino que también el trabajador es titular de derechos fundamentales inespecíficos o de la personalidad, vale decir derechos de los cuales es titular ya no solo en su calidad de trabajador sino de persona, que no son netamente laborales pero que se aplican a la relación de trabajo en cuanto son inherentes a la condición de ciudadano del trabajador".

57 Miranda con Montecarlo Administradora S.A., sentencia del 23 de septiembre de 2010, 20 Juzgado de Letras del Trabajo de Santiago, RIT T-179-2010: "la acción de tutela laboral introducida por el nuevo procedimiento laboral tiene por objetivo dotar a los trabajadores de un mecanismo de defensa de sus derechos ciudadanos, introduciendo el concepto de ciudadanía en la empresa desarrollado por la doctrina y de aplicación en la legislación comparada". 
vocamente por alguno como promotor de este concepto ${ }^{59}$, ha sostenido que pese a que "en el último tiempo se ha hecho frecuente ocuparla en sustitución a la idea de derechos fundamentales" ${ }^{60}$, en el ámbito laboral "la idea de ciudadanía puede mover a error"61. Dicho autor comparte la reflexión de Michelangelo Bovero según la cual "si los derechos del hombre (de la persona) son propiamente universales, es decir, le corresponden a cualquiera en su calidad de persona, los derechos del ciudadano son necesariamente particulares, al menos hasta que no se instituya una ciudadanía universal, cosmopolita" 62 .

En efecto, el gran problema con la concepción aquí criticada de ciudadanía laboral es que ella no gira en torno al ciudadano, inserto en una polis y marcado por las relaciones sociales que ha establecido en el seno de esta, sino que en torno al desnudo ser humano; a la persona, desprovista de identidad social pero investida con derechos fundamentales, abstractos y universales. Las estrategias argumentativas invocadas por la Dirección del Trabajo en su Ordinario No 2856/162 confirman esta afirmación importando el discurso neoconstitucional, para el cual los derechos fundamentales poseen efecto horizontal y pueden ser exigidos respecto de toda persona, institución o grupo ${ }^{63}$, por lo que todos los intercambios sociales deben ser regulados mediante rigurosos ejercicios de ponderación y análisis de proporcionalidad siempre susceptibles de escrutinio por parte de los tribunales mediante diversos estándares de racionalidad judicialmente ${ }^{64}$. Este es un esfuerzo de despolitización de la vida

59 Véase CaAmaño, Eduardo (2011). “La noción de acoso moral laboral o 'mobbing' y su reconocimiento por la jurisprudencia en Chile". Revista de Derecho de la Pontificia Universidad Católica de Valparaíso, Vol. 37, pp. 215-240, p. 216, nota 1.

60 Ugarte (2007) 115, nota 140.

61 Ugarte (2007) 115, nota 140.

62 Citado en Ugarte (2007) 116 , nota 140

63 Ordinario No 2856/162, Departamento Jurídico, Dirección del Trabajo, Fija sentido y alcance del inciso primero, del artículo 5o, del Código del Trabajo, 30 de agosto de 2002, p. 2: "los derechos fundamentales han de regir plenamente en cualquier ámbito, siendo oponibles, por tanto, no solo a los poderes públicos sino también a los sociales, desarrollando así una eficacia horizontal o pluridireccional”.

64 Ordinario No 2856/162, Departamento Jurídico, Dirección del Trabajo, Fija sentido y alcance del inciso primero, del artículo 50, del Código del Trabajo, 30 de agosto de 2002, p. 3-4: "los derechos fundamentales no son ilimitados o absolutos, reconocen como una consecuencia necesaria de la unidad de interpretación del ordenamiento constitucional ciertos límites a su ejercicio... cualquier limitación de los derechos fundamentales de la persona del trabajador en virtud del ejercicio de los poderes empresariales, solo resultará ajustada si está justificada constitucionalmente a través del juicio de proporcionalidad y si no afecta el contenido esencial del derecho de que se trata, análisis que ha de verificarse en cada caso en concreto".

Así, por ejemplo, el Ordinario No 2328/130, argumenta que "la instalación de dispositivos de control audiovisual, como una forma de control o vigilancia permanente y continuada, provoca en el trabajador, inexorablemente, un estado de tensión o presión incompatible con la dignidad humana”, afirmación en cuyo respaldo despliega el clásico examen tripartito 
social a través de su juridificación; la búsqueda en el derecho de un "dominio neutral en el cual no haya conflicto y se pueda alcanzar un acuerdo común a través del debate y los intercambios de opiniones" ${ }^{65}$. Recordemos la advertencia de Collins: la estrategia de derechos fundamentales puede fácilmente conducir a la descontextualización, la despolitización y la despolitización del espacio laboral. Lo más paradójico es que en el marco de esa estrategia sea invocado un concepto como el de ciudadanía, de contenido teórico y consecuencias políticas tremendamente precisas en la historia moderna. Esta invocación no solo distorsiona su claridad conceptual sino que, lo que es peor, transforma en irrelevante a este concepto. Si ciudadanía es eso, cualquier cosa puede ser ciudadanía.

La formulación de un concepto de ciudadanía laboral teóricamente correcto y políticamente relevante nos exige contar con un concepto preciso de ciudadanía, así como con una reflexión sobre las características específicas de la comunidad en cuyo seno se aspira a insertar la idea de ciudadanía. Tal concepto de ciudadanía debe partir por tomar nota del carácter autorreferencial o de 'segundo orden' de la ciudadanía, en cuanto ella habilita a sus titulares a participar en la determinación de sus propias titularidades. La ciudadanía, así, no consiste en la protección de intereses de alcance individual en la forma de derechos civiles; ni siquiera en la entrega de bienes o titularidades en la forma de derechos sociales. Todo ello puede ocurrir también en el seno de comunidades marcadas por la dominación o ausencia de ciudadanía ${ }^{66}$. Más concretamente, como ob-

de proporcionalidad emanado de la jurisprudencia constitucional alemana estructurado en torno a la idoneidad, necesidad y proporcionalidad estricta de la medida limitativa de derechos fundamentales. Asevera dicha resolución que la medida bajo escrutinio "constituye un atentado desproporcionado a la intimidad del trabajador" y envuelve "una limitación del derecho a la intimidad del trabajador no idónea a los fines perseguidos, al no cumplirse a sus efectos los requisitos propios de todo límite que se quiera imponer a un derecho fundamental y que omnicomprensivamente podemos englobar en la aplicación del denominado 'principio de proporcionalidad", en cuya virtud "se exige que la medida limitativa, en este caso el control audiovisual, sea la única capaz de obtener el fin perseguido, de forma tal que no exista otra forma de alcanzar dicho objetivo sin restringir el derecho o que fuese menos gravosa, lo que en la situación en análisis evidentemente no ocurre”. Ordinario No 2328/130, Departamento Jurídico, Dirección del Trabajo, Pronunciamiento sobre la legalidad del sistema de grabación de la imagen y el sonido, a través de videocámaras instaladas en los vehículos de la locomoción colectiva urbana recaido en solicitud de Sindicato Interempresa de Trabajadores de San Bernardo Las Condes, 19 de julio de 2002, pp. 5-6.

65 Schmitr, Carl (2007). "The age of Neutralizations and Depoliticizations". En Schmitt, Carl. The Concept of the Political. Chicago: The University of Chicago Press, 158 pp., p. 89.

66 Ello, sin perjuicio de que ambas categorías de derechos sean necesarias para dar solidez a la ciudadanía. Un ciudadano que carece de intimidad, propiedad o educación difícilmente podrá ejercer su ciudadanía. Desde esa perspectiva, los derechos sociales son tan importantes como los derechos civiles. El punto, como observa Pérez, es que una cosa es la dominación, un fenómeno político, y otra cosa es la explotación, un fenómeno económico; lo mismo vale para sus opuestos, la ciudadanía y las titularidades bienestaristas. Pérez, Carlos (2008) Para una crítica del poder burocrático: comunistas otra vez. Santiago: Lom, 224 pp., p. 160. 
serva Gamonal, “[p]odría darse el caso, hipotético, de una empresa que respetara todos los derechos ciudadanos del trabajador (a la intimidad, honra, libertad de expresión, etc.), pero con relaciones laborales deficientes, remuneraciones bajas y sin posibilidad de negociar colectivamente" 67 . Ahora bien, cabe preguntarse si en esta situación de 'bienestarismo paternalista' tendría sentido hablar de ciudadanía laboral. Quien responda negativamente a esta pregunta se verá conducido a compartir la intuición según la cual hay que buscar lo específicamente ciudadano en la capacidad de participar de la toma de decisiones.

\section{3) LA CIUDADANÍA LABORAL COMO EMANCIPACIÓN DE LA CLASE TRABAJADORA}

Mi propósito aquí es, a partir de la crítica a los usos discursivos anteriormente reseñados, construir una concepción positiva de ciudadanía, que a su vez sirva para darle contenido a un concepto correcto y relevante de ciudadanía laboral ${ }^{68}$. Me parece que la mejor forma de alcanzar dichos objetivos es regresar al contraste sugerido en el primer acápite entre dominación y ciudadanía; contrapunto que, según creo, permitirá comprender mejor la significación de la discusión sobre ciudadanía laboral.

A efectos de la presente discusión, entenderé dominación y ciudadanía como dos respuestas contrapuestas a preguntas cratológicas fundamentales que surgen dentro de todo grupo definido por su orientación hacia el hacer u organización ${ }^{69}$. Estas preguntas son las siguientes: ¿cómo se determinan las metas del grupo y los medios para alcanzarlas? Y, ¿cómo se determina la autoridad encargada de disciplinar ese proceso ${ }^{70}$ La do-

67 Gamonal (2004) 74.

68 Los planteamientos contenidos en esta sección ofrecen un concepto de ciudadanía laboral consistente con la teoría política. Tal consistencia nada dice, por supuesto, del atractivo de dicha propuesta, materia que cada lector deberá juzgar por sí mismo, ya sea en virtud de sus intereses o de sus concepciones morales.

69 Un grupo también puede estar definido en función de cualidades adscriptivas, esto es "en torno a características que mayormente están fuera del alcance de las personas”. GutManN, Amy (2008) La identidad en democracia. Buenos Aires: Katz, 308 pp., p. 170. En tal caso existe la posibilidad, ajena a los grupos orientados al hacer, de que las preguntas sobre la distribución del poder no emerjan en dicho contexto. Por supuesto, puede ser que sí lo hagan, en la forma de jerarquías inmanentes al grupo adscriptivo. Asimismo, puede ser que la identidad adscriptiva sea el punto de partida para el surgimiento de una organización. GuTMANN (2008) 170-171. El mismo Estado -esto es, el conjunto de las instituciones sometidas al principio de legalidad y orientadas a la satisfacción de necesidades públicas- es una organización que surge de una comunidad de carácter adscriptivo, la Nación.

70 Hay que decir aquí que la existencia de autoridades disciplinantes no es sinónimo de dominación. Una república, forma de gobierno estructurada en torno al concepto de ciudadanía, admite la existencia de autoridades disciplinantes; pero en este caso, la identidad y metas de las autoridades, y los poderes que se les reconocen para alcanzar tales objetivos, están deter- 
minación consiste en una respuesta excluyente y jerárquica: la determinación de metas, medios y autoridades es adoptada unilateralmente por alguien o algunos, sin involucrar a todos aquellos a los cuales las decisiones tomadas les afectarán ${ }^{71}$. La ciudadanía consiste en una respuesta igualitariamente inclusiva: tales determinaciones son tomadas involucrando a todos quienes serán afectados.

Dominación y ciudadanía deben ser vistos como tipos ideales que forman parte de un continuo y que, en consecuencia, pueden darse en diversos grados tanto en la realidad como en los sistemas de ideas y creencias que aspiran a regularla. Hay, por ejemplo, más dominación en la esclavitud que en la minoría de edad; y hay más ciudadanía en aquellos contextos donde hay posibilidades significativas de involucramiento en la deliberación y la toma de decisiones que en aquellos contextos donde no las hay. Debido a ello, es muy improbable que nos enfrentemos a propuestas que deseen hacer de la realidad pura dominación o pura ciudadanía. Más bien, lo que ocurre es que distintas concepciones morales y filosóficas nos ofrecerán distintas combinaciones entre dominación y ciudadanía.

Fijemos, entonces, nuestra atención en los fundamentos filosóficos que explican en nuestra sociedad la ubicación de la relación entre trabajadores y empleadores en el plano de la dominación. A fin de comprender esto, debemos atender a la comprensión liberal de la relación entre dominación y ciudadanía, que en esta materia puede ser considerada como históricamente hegemónica en el marco de la modernidad occidental. Me parece adecuado sostener que el imaginario político liberal emplea la distinción público/privado para administrar las áreas de ciudadanía y dominación: mientras que la dominación es rechazada en el espacio público, donde se dispone que los individuos concurrirán como iguales a la toma de decisiones colectivas, ella es aceptada en el espacio privado. Por ejemplo, dado que para el liberalismo clásico la familia forma parte de lo privado, entonces el liberalismo clásico acepta que existan relaciones

minados por la comunidad toda. Hay que tener en cuenta esta precaución al leer la afirmación de la Dirección del Trabajo según la cual "la estructura misma de la organización" -en este caso, de la empresa- "reconoce como elemento de su esencia la interacción jerarquizada de sus componentes”. Ordinario No 2856/162, Departamento Jurídico, Dirección del Trabajo, Fija sentido y alcance del inciso primero, del artículo 5o, del Código del Trabajo, 30 de agosto de 2002, p. 4. Así, esta afirmación sobre la esencialidad de la "interacción jerarquizada” al seno de una organización sería correcta si quisiera decir que es de la esencia de una organización contar con autoridades; pero sería incorrecta si quisiera decir que es de la esencia de una organización contar con autoridades determinadas en función de su acceso a la propiedad (cosa que ni aún en el caso de la organización conocida como 'empresa' es necesariamente cierta, ni mucho menos aún moralmente correcta).

71 La dominación tiene una estrecha correlación con la desigualdad. Así, por ejemplo, una desigual distribución de recursos implica a menudo una desigual distribución de la posibilidad de expresar los intereses y convicciones de cada quien, así como de la posibilidad de involucrarse significativamente en la toma de decisiones colectivas. 
de dominación entre padres e hijos o entre marido y mujer. Desde esas perspectivas, diversas transformaciones del derecho de familia ocurridas durante el último siglo, incluyendo la igualdad civil entre cónyuges y la punición efectiva de la violencia intrafamiliar o la reducción de la patria potestad, representan un paulatino desplazamiento de la familia desde lo privado hacia lo público, aunque no representan necesariamente una alteración del paradigma liberal, que asocia la ciudadanía a lo público y la dominación a lo privado, en sí mismo.

Vamos ahora a la relación entre trabajadores y empleadores. El trabajo asalariado, en la forma que ha adoptado paradigmáticamente desde la Revolución Industrial, constituye una forma de relación social estructurada en torno a la dominación de unos, los dueños del capital, por sobre otros, aquellos que carecen de capital. Esta relación es de dominación en cuanto (a) la determinación abstracta de las metas que deberá alcanzar el trabajador y los medios para alcanzarlas le corresponde unilateralmente al dueño del capital, y (b) la determinación de los sujetos específicos que tomarán las decisiones ya señaladas es también realizada por los dueños del capital ${ }^{72}$. El concepto jurídico que posibilita esta relación, así como la localización de esta relación dentro del ámbito de lo privado es el de propiedad, que en su comprensión liberal decimonónica está concebido como un derecho a disponer de una cosa 'arbitrariamente', al decir de nuestro Código Civil, o 'de la manera más absoluta', en palabras del Código de Napoleón ${ }^{73}$. Quien es dueño del capital es dueño también de los medios de producción, y puede disponer de ellos 'arbitrariamente' y 'de la manera más absoluta'. El trabajador es, respecto de todo ello, un tercero. Un tercero con intereses, desde luego, tales como el interés de ganarse la

72 Por supuesto, existen casos en que ello no es así. Por ejemplo, un determinado trabajador puede encontrarse en la libertad de determinar sus metas o bien de determinar los medios para cumplirlo. Así por ejemplo, en el marco de nuestra relación laboral con la Universidad Austral de Chile, yo y los demás académicos que formamos parte de la planta académica debemos cumplir con ciertas metas de producción que incluyen impartir una cierta cantidad de asignaturas de pregrado y realizar actividades investigativas que se traduzcan en la publicación de cierta cantidad de trabajos académicos. Ahora bien, las asignaturas que impartiremos y nuestras actividades investigativas estarán, por lo general, estrechamente relacionadas con nuestros intereses o inquietudes vocacionales, lo que entrega un margen razonable de autonomía y autorrealización personal. Asimismo, un trabajador puede encontrarse en la posibilidad de participar en la determinación de sus autoridades. En el mismo ejemplo, los académicos de la misma institución detentamos el derecho a participar de la elección de quienes desempeñen los cargos directivos de la institución, incluyendo directores de instituto, decanos, y rector. Es en casos como este es que podríamos hablar de la existencia de ciudadanía laboral.

La mención del párrafo anterior a la autorrealización personal nos sugiere que la dominación está íntimamente vinculada a otro fenómeno denunciado por la crítica marxista del proceso de producción capitalista: la ejanenación. Véase Pérez (2008) 119 y ss.

73 Sobre las transformaciones históricas del concepto de propiedad, véase Cordero, Eduardo y Aldunate, Eduardo (2008) "Evolución histórica del concepto de propiedad". Revista de estudios histórico-jurídicos, Vol. 30, pp. 345-385. 
vida mediante una actividad que involucre el ejercicio pleno de sus facultades intelectuales y morales y no solo la fuerza física o el cumplimiento de instrucciones; pero, como tales, intereses que al fin y al cabo no están jurídicamente protegidos, por lo que no alcanzan a configurar aquel 'derecho ajeno' que el artículo 582 del Código de Bello reconoce como limitación a la propiedad.

Ahora bien, si por un lado la relación de dominación es posibilitada por el concepto de propiedad, por el otro ella es regulada en beneficio de la parte más débil en la forma de la reglamentación legal del contrato individual de trabajo ${ }^{74}$, la que toma la forma de restricciones a la libertad contractual de ambos contratantes. A fin de asegurar la efectividad de dicha reglamentación, el derecho del trabajo acuña el concepto de subordinación y dependencia, el cual 'tipifica' aquella relación social que el legislador ha tenido en consideración al momento de formular la reglamentación en cuestión. En consecuencia, el derecho individual del trabajo mantiene una relación compleja con la dominación: por un lado, la reconoce en la forma de la subordinación y dependencia, validándola jurídicamente; por el otro, el propósito con el que lo hace es declaradamente protector ${ }^{75}$. En ese sentido es un derecho paternalista, no emancipador.

Ahora, si el derecho individual del trabajo -esto es, la restricción paternalista de la libertad contractual del trabajador- no tiene un carácter emancipador -esto es, no es apto para producir el paso desde la esfera de la dominación hacia aquella de la ciudadanía-, cabe preguntarse lo siguiente: ¿existe, al menos a nivel conceptual, algún instrumento jurídico que pueda operar tal desplazamiento?

La respuesta habría que extraerla de todos aquellos casos históricos en los cuales sujetos previamente excluidos o dominados pasaron a ser incluidos o a ser considerados ciudadanos. Los 'casos fáciles', como cabe esperar dentro de una historia como la occidental influenciada principal-

74 En nuestro país, ello ocurre a partir de la aprobación de la Ley No 4.053 sobre contrato de trabajo, en la versión enviada al Congreso por Arturo Alessandri en 1921 y promulgada apresuradamente el 8 de septiembre de 1924 tras el así llamado ruido de sables del día 2 del mismo mes. En términos más abstractos, ello ocurre en Occidente tras el surgimiento del derecho laboral como respuesta a la politización de la 'cuestión social' por parte de los movimientos de trabajadores.

75 Tal complejidad se replica en la relación del derecho del trabajo con el liberalismo jurídico. Por un lado su epistemología, que reconoce jurídicamente una importante desigualdad social, representa un paso adelante respecto del liberalismo, el cual desecha a las desigualdades sociales del conjunto de información jurídicamente relevante en nombre de la igualdad ante la ley y de la autonomía contractual. Por otro lado, la estrategia institucional que adopta el derecho laboral replica aquella que caracteriza al liberalismo jurídico en su lucha contra el poder estatal: establecer un coto vedado donde el más poderoso -el Estado, en el derecho privado liberal; el empleador, en el derecho laboral- no puede ingresar. En eso, y no en otra cosa, consiste la incorporación o importación de los derechos fundamentales y de la mal llamada 'ciudadanía laboral' al ámbito de la relación de trabajo. 
mente por las tradiciones liberal y republicana, son aquellos que involucran el proceso político-electoral, ámbitos indiscutiblemente situados en el dominio de lo público. Esto no significa que la concesión de derechos electorales y políticos a personas carentes de propiedad, a la mujer o a las minorías étnicas haya sido cosa fácil; significa que para justificar dichas exclusiones, los opositores debieron hacer esfuerzos por demostrar que el sujeto excluido en cuestión carecía de los atributos intelectuales y morales que sustentan subjetivamente la ciudadanía, o bien renunciar a la justificación pública e intentar mantener dicha exclusión mediante vías de hecho tales como el amedrentamiento o el cohecho. Una vez alcanzado el acuerdo público sobre la necesidad de incluir al sujeto colectivo en cuestión, sin embargo, la ejecución o implementación de dicho acuerdo involucró prácticamente en todos los casos grandes esfuerzos y siempre se cumplió de manera tan solo parcial. Así, por ejemplo, hasta el día de hoy en Chile hay disparidades significativas entre 'ricos' y 'pobres' en el ejercicio del derecho a sufragio; la mujer tiene en todo Occidente una participación menguada en cargos de representación política y autoridad; y la población afroamericana de Estados Unidos ve constantemente dificultada o incluso amenazada su participación del proceso electoral en los antiguos estados de la Confederación.

Si se toman en cuenta las dificultades que la concesión de ciudadanía ha afrontado incluso en el espacio más reconocidamente público, que es el proceso político-electoral, queda claro que su realización es mucho más difícil en un espacio como la empresa; el que, para quien haya desarrollado sus convicciones filosóficas bajo el influjo de instituciones liberales, estará intuitivamente ubicado en el espacio de lo privado y de la propiedad. Esto no significa que sea imposible; la propia existencia del derecho laboral representa una rada pública tendida hacia el seno del espacio privado de la empresa. Adicionalmente, por supuesto, la dificultad fáctica de una propuesta no constituye en sí una objeción moral contra la propuesta de ciudadanía laboral; simplemente, nos habla de lo improbable de que ella sea llevada a cabo en virtud de su radicalidad, es decir de su ubicación más allá de lo considerado como probable en el contexto actual. Una vez más, eso tampoco dice mucho más de lo allí expresado; muchos de los desarrollos políticos de los últimos tres siglos, incluyendo la idea misma de sufragio universal, también habrían sido considerados como radicales en períodos anteriores de la historia.

Asumiendo la radicalidad de lo que conlleva pensar en la materia, queda claro que la ciudadanía del trabajador solo se puede conquistar a costa del espacio socioeconómicamente definido de dominación; esto es, a costa del espacio ocupado por el concepto jurídico de subordinación y dependencia. ¿Y cuáles son los contenidos de dicho espacio y de dicho concepto? La clave se encuentra escondida en los vericuetos de la 
jurisprudencia administrativa de la Dirección del Trabajo, sepultada entre consideraciones sobre la ponderación y el juicio de proporcionalidad. Dice allí la Dirección del Trabajo que "al empresario le es reconocido el ejercicio de una serie de facultades o prerrogativas que tienen por objeto el logro del referido proyecto empresarial en lo que al ámbito laboral se refiere, y que responden a lo que genéricamente se denomina poder de dirección"76. Estas facultades o prerrogativas, observa la Dirección del Trabajo, "se traducen en la libertad para contratar trabajadores, ordenar las prestaciones laborales, adaptarse a las necesidades de mercado, controlar el cumplimiento y ejecución del trabajo convenido, y sancionar las faltas o los incumplimientos contractuales del trabajador": el poder empresarial $^{77}$.

Es partir de este listado que se puede edificar dialécticamente una auténtica noción de ciudadanía laboral. Solo puede existir ciudadanía laboral en la medida en que existan espacios de toma de decisiones al interior de las empresas; espacios para tomar decisiones sobre la adaptación a las demandas productivas, la incorporación de otros trabajadores, la ordenación de las prestaciones laborales, el control del cumplimiento y ejecución del trabajo, y la sanción de las faltas o los incumplimientos contractuales del trabajador. Espacios que reconozcan participación tanto al obrero, constructor o transportista como al ingeniero, abogado o accionista. Esta participación debe involucrar el derecho de los trabajadores a contar con información sobre el proceso productivo y a deliberar sobre este, así como el poder de elegir representantes ante el órgano de toma de decisiones. Así, habrá ciudadanía laboral solamente allí donde los trabajadores sean ciudadanos al interior de sus lugares de trabajo. Si no hay trabajadores que sean ciudadanos al interior de sus lugares de trabajo, entonces ocurre que no hay ciudadania laboral.

Esta forma de entender la ciudadanía laboral implica una forma alternativa de entender el esfuerzo marshalliano de expandir el ámbito de la ciudadanía. Así, si Marshall la transforma en un estatuto de contenidos históricamente contingente, que gana un elemento bienestarista durante la posguerra y lo pierde durante el contraataque neoliberal, mi planteamiento, en cambio, preserva la comprensión de la ciudadanía como un derecho a participar -comprensión común a las concepciones liberales y republicanas de este concepto- pero la lleva a un nuevo ámbito, en este caso el de la producción. El resultado es una politización del espacio la-

\footnotetext{
76 Ordinario No 2328/130, Departamento Jurídico, Dirección del Trabajo, Pronunciamiento sobre la legalidad del sistema de grabación de la imagen y el sonido, a través de videocámaras instaladas en los vehículos de la locomoción colectiva urbana recaido en solicitud de Sindicato Interempresa de Trabajadores de San Bernardo Las Condes, 19 de julio de 2002, p. 3.

77 Ordinario No 2856/162, Departamento Jurídico, Dirección del Trabajo, Fija sentido y alcance del inciso primero, del artículo 50, del Código del Trabajo, 30 de agosto de 2002, p. 4.
} 
boral en el sentido de esta expresión que le es propio al derecho colectivo del trabajo; esto es, una institucionalización del conflicto de clases mediante la creación de mecanismos que le permitan a la clase trabajadora participar en igualdad de condiciones del conflicto laboral. Por otro lado, una concepción tal de ciudadanía laboral representaría un esfuerzo por separar, al interior de la organización productiva, el acceso a la propiedad de la participación en la toma de decisiones, en un movimiento o transformación similar a la experimentada por la propia ciudadanía política en el paso de la democracia censitaria al sufragio universal ${ }^{78}$.

Esto no significa, al menos no conceptualmente, que la ciudadanía deba ser la única consideración que estructure la toma de decisiones al interior de la empresa. Perfectamente ella, que iguala la voluntad de todos los integrantes de la organización, puede coexistir con la experticia, que establece gradaciones o jerarquías de acuerdo al conocimiento que se ten$\mathrm{ga}^{79}$. Eso no es problema; el Estado moderno es evidencia de que democracia y experticia pueden coexistir ${ }^{80}$. Las preguntas, en cambio, son de otro tipo: ¿existe voluntad colectiva para establecer un régimen de ciudadanía laboral? ¿Existen razones de bien común que aconsejen hacerlo? La primera cuestión solo puede responderla el proceso político. La segunda involucra elaborar, a partir de la crítica a la explotación o apropiación del valor producido por otros, una teoría positiva sobre lo debido al trabajador; una teoría proletaria de la justicia, si se quiere ${ }^{81}$.

78 El artículo $8^{\circ}$ de la Constitución de 1833 atribuía la condición de "ciudadanos activos con derecho de sufragio", entre otros requisitos, a los hombres que tuvieren "una propiedad inmueble, o un capital invertido en alguna especie de giro o industria", o bien desempeñaran "el ejercicio de una industria o arte, o el goce de algún empleo, renta o usufructo, cuyos emolumentos o productos guarden proporción con la propiedad inmueble, o capital de que se habla en el número anterior". Estos dos requisitos fueron eliminados mediante la ley de reforma constitucional de 9 de agosto de 1888 .

79 Sin embargo, nada hace suponer a priori que la experticia no estará en manos de los trabajadores. Es más, una propuesta de ciudadanía laboral involucra el acceso efectivo de los trabajadores a las fuentes de información sobre la unidad productiva, incluyendo información fidedigna sobre sus costos operacionales.

80 Véase Fisher, Frank (2009) Democracy and Expertise: reorienting policy inquiry. Oxford: Oxford University Press, 304 pp.

81 Para una reivindicación y reelaboración de la crítica de la explotación, véase Pérez (2008). La obra de Gerald Cohen, en general, es lo más cercano que existe hoy en día a una teoría proletaria de la justicia, aunque sea en virtud del reconocimiento que el propio Cohen hace de la influencia de sus orígenes familiares y políticos en su filosofía política igualitaria. Véase, por ejemplo, Cohen, Gerald (2011) ¿Por qué no el socialismo? Buenos Aires: Katz, 64 pp.

Por cierto, me parece que queda abierta a la discusión la posibilidad misma de construir una teoría proletaria de la justicia, debido a la epistemología crítica que acompañaría al esfuerzo de pensar sobre la justicia desde tal posición, cosa que ocurre también en el caso de los intentos por elaborar semejantes propuestas desde el feminismo o la teoría crítica de raza. La pregunta previa, en consecuencia, sería cuáles serían los registros académicos apropiados para la crítica a la dominación capitalista. 
En términos ya más instrumentales, me parece que los dos pasos necesarios para poder hablar de la existencia de ciudadanía laboral son el estatuir dispositiva y perentoriamente la afiliación sindical de los trabajadores, y el incorporar por ley a representantes de los trabajadores a los directorios de las sociedades anónimas. El primer paso exige eliminar la voluntariedad de la afiliación sindical, establecida en el artículo 19 No 19 de la Constitución, reemplazándolo por la membresía automática en sindicatos existentes por la sola voluntad de la ley ${ }^{82}$. La idea de la voluntariedad en la constitución de sindicatos y la afiliación a ellos, desde luego, constituye un elemento central del credo jurídico (neo)liberal; su presupuesto es la autonomía y suficiencia del individuo. Ahora bien, en sí mismo el derecho del trabajo históricamente ha representado un alejamiento de algunas de las conclusiones de dicha premisas, tales como la suficiencia de los individuos en cuanto negociadores contractuales ${ }^{83}$. ¿Qué impide que el derecho laboral también abandone la idea de la voluntariedad en la constitución de sindicatos y la afiliación a ellos? ¿Sería acaso una objeción el que la ley dispondría de manera inconsulta nuestra membresía en una organización? ¿O el que en el caso de que no deseáramos participar activamente de ella, quienes sí lo hicieran estarían tomando decisiones que nos afectan también de manera inconsulta? Habría que responder que la 'inscripción sindical automática' no sería diferente de lo existente en dos situaciones donde nadie podría afirmar seriamente que exista un abuso de la libertad individual: en primer lugar, en la propia membresía individual de cada uno de nosotros en el electorado ${ }^{84}$; en segundo lugar, en la membresía de los estudiantes universitarios en centros de alumnos y fede-

82 Nótese que el significado de la modificación propuesta es bastante modesto; tan solo significa que la existencia de sindicatos en cada unidad productiva estaría dispuesta por la ley, debiendo la misma contemplar mecanismos para que los trabajadores pudiesen hacer efectiva tal existencia, y que todos los trabajadores de dicha unidad serían parte de dicho sindicato de pleno derecho. Ahora bien, la participación efectiva en ellos seguiría dependiendo de la decisión de cada individuo de concurrir a los procesos electorales, participar de ellos como candidatos, asistir a las reuniones organizadas por el sindicato, y así sucesivamente.

83 "El modelo contractual de la locatio operarum, o arrendamiento de servicios, que construido sobre el horizonte del derecho romano concibe el contrato como un acuerdo entre iguales, expresada en una exigua regulación legal (normas de arrendamiento de servicios de los Códigos Civiles), no estaba en condiciones de dar un cauce jurídico idóneo a la nueva realidad de empleo masivo de trabajadores creada por la revolución industrial, de modo que dicha insensibilidad social no le permitía cumplir con la función que se requería de la regulación jurídica del trabajo en el nacimiento del capitalismo". UGarTe (2008) 2-3.

84 Desde la entrada en vigencia de la Ley No 20.337, y en virtud de los artículos 13 y 15 de la Constitución Política de la República, la calidad de 'ciudadano' -esto es, de integrante del electorado o, como lo llama el artículo $5^{\circ}$, del 'pueblo'- se adquiere automáticamente por todos los chilenos al cumplir dieciocho años, y el ejercicio efectivo de las titularidades conferidas por dicha condición -particularmente, el derecho de sufragio y de optar a cargos de elección popular- queda entregado a las decisiones del individuo. 
raciones de estudiantes ${ }^{85}$. Hasta donde entiendo, nunca nadie ha sugerido que esta atribución de la calidad de 'ciudadano' que hace inconsultamente la ley constituya un abuso, ni tampoco que aquellos que se mantienen al margen del proceso electoral puedan exigir que las decisiones allí tomadas no les sean aplicables. Lo mismo ocurre con los centros de alumnos y federaciones de estudiantes; tampoco se estima que la pertenencia de pleno derecho a un centro de alumnos o federación así constituida violente a los alumnos, o que sus decisiones no les sean oponibles a quienes se resten de su participación. Por último, cabe señalar que nuestro ordenamiento jurídico, compatibilizando la eficacia colectiva con la libertad individual, no le exige quórums mínimos de participación ni al electorado ni al estudiantado para darle validez a las decisiones colectivas de quienes sí participan en sus respectivos procesos electorales. Tampoco tendría por qué exigírselas a los sindicatos.

El segundo paso sería modificar el artículo 31 de la Ley No 18.046 sobre sociedades anónimas para establecer allí la obligación de contar con directores elegidos por los trabajadores vinculados a la corporación en cuestión. Para los casos de empresas que no funcionen como sociedades anónimas, sino bajo otras figuras jurídicas, o tal vez bajo ninguna, bastaría con establecer un estatuto general supletorio que estableciera mecanismos de participación y consulta por parte de los trabajadores vinculados a una unidad productiva ${ }^{86}$. Una vez fortalecido el derecho laboral colectivo, otras reformas se sugerirán a sí mismas, tales como reemplazar la voluntariedad de la negociación interempresa, establecida en el artículo 334 bis A del Código del Trabajo, por su carácter vinculante. Otras más serán el resultado de la participación de los trabajadores en la toma de decisiones, y responderán a las demandas que ellos mismos visualicen y articulen desde esta nueva posición de poder. El horizonte normativo último, en todo caso, es sustraer a la empresa, en cuanto unidad productiva orientada a la satisfacción de necesidades humanas, del ámbito de la regulación civil y constitucional que hoy caracteriza a la propiedad individual, para así situarla en el espacio del bien común; una meta, ciertamente, que el lenguaje jurídico del presente es simplemente incapaz de formular, pero que

85 Basta con ser alumno regular de una institución educacional para ser parte de una de estas organizaciones, y allí donde no existan con agrupar a personas que se encuentren en dicha condición para dar existencia a una de ellas; a menos, claro, que la institución en cuestión las haya prohibido contra legem, más específicamente en contravención a lo dispuesto por el artículo 19 No 15 de la Constitución Política de la República.

86 Se podría observar que dichos mecanismos de participación y consulta debieran integrar a otros grupos afectados por las decisiones de la empresa, tales como sus consumidores o incluso el público en general. Esto, que me parece correcto, apunta a la inconsistencia filosófica que afecta al dominio privado del proceso productivo, el que satisface necesidades sociales y en consecuencia debiera estar regido por un estatuto que dé cuenta de su rol dentro de la consecución del bien común. 
en términos filosóficos ha quedado plasmado en la conocida fórmula "De cada cual, según su capacidad; a cada cual según sus necesidades" 87 .

En resumen, la única forma en que el derecho laboral puede emancipar a la clase trabajadora es destruyendo las bases materiales que permiten su propia existencia actual; es decir, la relación socialmente existente de relación y dependencia que vincula a empleadores y trabajadores. Y para ello es imprescindible entender que emancipar a la clase trabajadora suprimiendo la dominación al interior de la empresa es distinto de contener los efectos más abominables de la dominación al interior de la empresa; es decir, que ciudadania no es lo mismo que privacidad.

\section{A MODO DE CONCLUSIÓN}

¿Qué explica el recurso innecesario al concepto de ciudadanía para identificar la protección de la intimidad y la privacidad en el contexto laboral? Hay aquí, ciertamente, una deficiencia conceptual; una falta de imaginación jurídica por parte de jueces, abogados y académicos que, como ya he criticado en otra parte ${ }^{88}$, no logran emplear las categorías de lo público y de lo político para proteger a los trabajadores. Casi parecería como si la comunidad jurídica se hubiese contagiado de aquel mal que caracteriza a nuestro discurso público hoy en día en virtud del cual, dado el desprestigio de la institucionalidad formal, se hacen esfuerzos para aplicar la etiqueta de 'ciudadano' a todo aquello que nos parezca bien.

Sin embargo, tomar el guante y reflexionar consideradamente sobre qué involucraría un concepto teóricamente correcto de ciudadanía laboral nos releva que el verdadero problema es real, no conceptual; esto es, no se trata tan solo de un problema de ideas sino que de estructuras sociales. En el proceso productivo, tal como conocemos, el trabajador vive sometido a una autoridad en cuya generación no ha tenido parte, y de cuyas decisiones no toma parte alguna. No es aventurado sugerir, al menos como hipótesis, que este diseño institucional influye decididamente en la distancia que suele mediar en nuestra sociedad entre el trabajo imaginado idealmente como espacio de autorrealización y el trabajo experimentado realmente como necesidad material de sobrevivencia. Ante esto, usar el concepto de ciudadanía para aplaudir algo tan minimalista como la protección de la honra o la intimidad del trabajador no es sino un blan-

\footnotetext{
87 Marx, Karl (1972) Critica del Programa de Gotha. Santiago: Quimantú, 109 pp., p. 20.

88 MuÑoz, Fernando (2011). "ANEF con SII: ¿̨ibertad sindical, debido proceso o libertades públicas?”. Ius et Praxis, Vol. 17, pp. 537-550.
} 
queamiento de la estructura de explotación y de enajenación inserta en la relación laboral contemporánea ${ }^{89}$.

La ciudadanía laboral es, en consecuencia, un proyecto a realizar en las estructuras socialmente existentes, en la 'sociedad real'; no un término que pueda ser exitosamente integrado al repertorio discursivo de nuestro derecho tal como hoy en día existe. Es, sin duda, un proyecto tremendamente importante, pues consiste en un esfuerzo por superar la situación de dominación en la que viven todos aquellos trabajadores que no tienen voz ni voto en la determinación de sus condiciones de trabajo, y la situación de explotación que habitualmente está aparejada a aquella. Cosa distinta, por supuesto, es preguntarse si alguna vez este proyecto será realizado. Pero esa es una pregunta que habrá de ser respondida en otro espacio.

\section{BIBLIOGRAFÍA}

- Ackerman, Bruce (1991) We the People: Foundations. Cambridge: Harvard University Press, $369 \mathrm{pp}$.

- Alonso, Luis (2007) La Crisis de la Ciudadanía Laboral. Barcelona: Anthropos, $287 \mathrm{pp}$.

- Arendt, Hannah (1965) On Revolution. New York: Penguin Books, $368 \mathrm{pp}$.

- Auroux, Jean (1981) Les Droits Des Travailleurs: Rapport au Président de la République et au Premier ministre. Paris: Collection des rapports officiels La Documentation Francaise, 82 pp.

- Bateman, Thomas y Organ, Dennis (1983). "Job Satisfaction and the Good Soldier: The Relationship between Affect and Employee 'Citizenship'". The Academy of Management Journal, Vol. 26, pp. 587-595.

- CaAmaño, Eduardo (2011). "La noción de acoso moral laboral o 'mobbing' y su reconocimiento por la jurisprudencia en Chile".

89 Podría darse el caso, desde luego, de que el lector estimara que en la sociedad contemporánea no existe algo así como la enajenación, la explotación, o la dominación; y que en su opinión dichos términos tienen un carácter propagandístico, no académico. Si así ocurriera, la única forma de demostrarle a tal lector su error sería invitarlo a preguntarse porqué motivo, como es altamente probable que sea el caso, él o ella ha optado por una de las así llamadas 'profesiones liberales' -que, en el caso de los lectores de este texto, probablemente sea la de abogado o profesor universitario- en lugar de haber optado por alguno de los oficios en los que habitualmente pensamos cuando se nos pide pensar en un 'trabajador', tales como conductor de vehículos motorizados, obreros, secretarias, entre otros. Las respuestas a esta pregunta, que frecuentemente incluirán el nivel de ingresos de las 'profesiones liberales' y la posibilidad de ser 'el jefe de uno mismo', constituyen percepciones intuitivas de los fenómenos sociales a que los términos de 'explotación' y 'dominación' pretenden conceptualizar de forma sistemática. 
Revista de Derecho de la Pontificia Universidad Católica de Valparaíso, Vol. 37, pp. 215-240.

- Cohen, Gerald (2011) ¿Por qué no el socialismo? Buenos Aires: Katz, 64 pp.

- Collins, Hugh (1984) Marxism and Law. Oxford: Oxford University Press, 159 pp.

- Collins, Hugh (2010) Employment Law. Oxford: Oxford University Press, 265 pp.

- Cordero, Eduardo y Aldunate, Eduardo (2008) "Evolución histórica del concepto de propiedad". Revista de estudios históricojurídicos, Vol. 30, pp. 345-385.

- Craig, Edward (1998) Routledge Encyclopedia of Philosophy, Vol. 7. London: Routledge, 868 pp.

- Eagleton, Terry (1991) Ideology: an introduction. London: Verso, $242 \mathrm{pp}$.

- Fisher, Frank (2009) Democracy and Expertise: reorienting policy inquiry. Oxford: Oxford University Press, $304 \mathrm{pp}$.

- Flyvbjerg, Bent (2001) Making Social Science Matter: Why Social Inquiry Fails and How it Can Succeed Again. Cambridge: Cambridge University Press, 216 pp.

- France, Anatole (1921) The red lily, London: John Lane, 325 pp.

- Gamonal, Sergio (2004) Ciudadanía en la empresa o los derechos fundamentals inespecíficos. Montevideo: Fundación de Cultura Universitaria, $77 \mathrm{pp}$.

- Gerring, John (2001) Social Science Methodology: A Criterial Framework. Cambridge: Cambridge University Press, 324 pp.

- Giddens, Anthony (1998) The Third Way: The renewal of social democracy. Cambridge: Polity Press, $166 \mathrm{pp}$.

- Gregory of Tours (1991) The History of the Franks. New York: Penguin, $720 \mathrm{pp}$.

- Gutmann, Amy (2008) La identidad en democracia. Buenos Aires: Katz, 308 pp.

- Hirschman, Albert (1991) The Rhetoric of Reaction: Perversity, Futility, Jeopardy. Cambridge: Harvard University Press, 197 pp.

- Kant, Immanuel (2000) Crítica de la Razón Pura. ¿Qué es Ilustración? Zaragoza: Publicacions de la Universitat de València, 92 pp.

- Laclau, Ernesto y Mouffe, Chantal (2001) Hegemony and Socialist Strategy. London: Verso, 240 pp.

- Luhmann, Niklas (1992). "Operational closure and structural coupling: the differentiation of the legal system". Cardozo Law Review, Vol. 13, pp. 1419-1441.

- Marshall, Thomas (2006). "Citizenship and Social Class". En Pierson, Christopher y Castles, Francis (editores). The Welfare State Reader. Cambridge: Polity Press, pp. 30-39. 
- Marx, Karl (1972) Crítica del Programa de Gotha. Santiago: Quimantú, 109 pp.

- Muñoz, Fernando (2011). "ANEF con SII: ¿libertad sindical, debido proceso o libertades públicas?”. Ius et Praxis, Vol. 17, pp. 537-550.

- Novoa, Eduardo (1983) Derecho, política y democracia: un punto de vista de izquierda. Bogotá: Editorial Temis, 229 pp.

- Pérez, Carlos (2008) Para una critica del poder burocrático: comunistas otra vez. Santiago: Lom, $224 \mathrm{pp}$.

- Peтtit, Philip (1997) Republicanism: A Theory of Freedom and Government. Oxford: Oxford University Press, $388 \mathrm{pp}$.

- Podsakoff, Philip, MacKenzie, Scott y Organ, Dennis (2006) Organizational Citizenship Behavior: Its Nature, Antecedents, and Consequences. Thousand Oaks: Sage, $360 \mathrm{pp}$.

- SARtori, Giovanni (2011) Logica, metodo e linguaggio nelle scienze sociali. Bologna: Società Editrice Il Mulino, $288 \mathrm{pp}$.

- Schmitt, Carl (2007). "The age of Neutralizations and Depoliticizations". En Schmitt, Carl. The Concept of the Political. Chicago: The University of Chicago Press, 158 pp.

- Tironi, Eugenio (1984) La Torre de Babel. Ensayos de critica y renovación política. Santiago: Ediciones Sur, 157 pp.

- Ugarte, José Luis (2007) El nuevo derecho del trabajo. Santiago: Lexis Nexis, 262 pp.

- Ugarte, José Luis (2008) La subordinación en el derecho laboral chileno. Santiago: Legal Publishing, 76 pp.

- Valdés, Juan Gabriel (1995) Pinochet's Economists: The Chicago School in Chile. Cambridge: Cambridge University Press, $334 \mathrm{pp}$.

- Walker, Francisco (1948). "Legislación Social de Chile". Anales de la Facultad de Ciencias Jurídicas y Sociales, Vol. 13, No 52-59, p. 33-41. 